\title{
A FISIOTERAPIA E A SAÚDE COLETIVA NO BRASIL: UMA REVISÃO BIBLIOGRÁFICA
}

*LEAL, Daiane Pontes; SANTOS, Wine Suélhi dos; LEITE, Pedro de Sousa

Faculdade Leão Sampaio - Juazeiro do Norte (CE), Brasil.

Faculdade de Medicina Estácio de Juazeiro do Norte - Juazeiro do Norte (CE), Brasil.

Recebido em: 08/04/2015; Aceito: 22/04/2015; Publicado: 25/08/2015

\section{RESUMO}

O profissional fisioterapeuta atua no nível primário executando ações de promoção, prevenção e educação em saúde, no nível secundário realizando diagnóstico prévio e o respectivo tratamento, e, no nível terciário, age diretamente no processo de reabilitação, minimizando as incapacidades. O objetivo deste trabalho foi revisar na literatura a inserção da Fisioterapia na Saúde Coletiva no Brasil. Desse modo, foi executada uma busca nas seguintes bibliotecas virtuais: SCIELO, LILACS, BVS, e Google Acadêmico. Além disso, para acessar as leis, decretos, regulamentos e portarias sobre a Fisioterapia e sua atuação no âmbito público, foram acessados o Conselho Federal de Fisioterapia e Terapia Ocupacional e os documentos do Ministério da Saúde. Foram selecionadas publicações que versassem sobre a Fisioterapia na saúde pública. Diante do exposto, conclui-se que a participação do fisioterapeuta é imprescindível na saúde pública, em todos os níveis, visto que esse profissional encontra-se habilitado para desenvolver ações primárias de saúde, sem perder a sua relevância na reabilitação. No entanto, essa função do fisioterapeuta ainda é pouco conhecida até mesmo entre os profissionais da saúde e pelos usuários de saúde.

Palavras-chave: Fisioterapia, Saúde Coletiva, Ações Primárias de Saúde.

\begin{abstract}
The professional physiotherapist operates in primary running promotion, prevention and health education at the secondary level performing previous diagnosis and its treatment, and, at the tertiary level, acts directly in the rehabilitation process, minimizing disability. The objective of this study was to review the literature insertion of physiotherapy in Public Health in Brazil. Thus, a search was performed in the following virtual libraries: SCIELO, LILACS, VHL, and Google Scholar. In addition, to access the laws, decrees, regulations and ordinances on physical therapy and its performance in public life, were accessed the Federal Council of Physical Therapy and Occupational Therapy and the Ministry of Health documents. Publications were selected that about physiotherapy in public health. Given the above, it is concluded that the participation of the physiotherapist is essential, public health, at all levels, since this professional is enabled to develop primary health actions, without losing its relevance in rehabilitation. However, this physical therapist's role is still unknown even among health professionals and the health of users.
\end{abstract}

Keywords: Physical Therapy, Public Health, Health Primary actions.

*Daiane Pontes Leal; Rua André Cartaxo, 917. Bairro Palmeiral, Crato, Ceará. e-mail: daianeleal@ leaosampaio.edu.br ; Telefone: (88) 999122413 


\section{INTRODUÇÃO}

Dentre as diversas situações que agravam a saúde, a atenção básica juntamente com sua equipe multidisciplinar, surge como peça fundamental para a promoção de saúde e a prevenção de doenças e agravos na sociedade (DELAI; WISNIEWSKI, 2011).

Nesse contexto da multidisciplinaridade, o profissional fisioterapeuta possui importante papel, já que enriquece os cuidados à saúde com seus conhecimentos generalistas e ainda por desenvolver a saúde em todos os seus níveis (JÚNIOR, 2010).

A Fisioterapia é definida como uma ciência da Saúde que estuda, previne e trata os distúrbios cinéticos funcionais intercorrentes em órgãos e sistemas do corpo humano, gerados por alterações genéticas, por traumas e por doenças adquiridas. Fundamenta suas ações em mecanismos terapêuticos próprios, sistematizados pelos estudos da biologia, das ciências morfológicas, das ciências fisiológicas, das patologias, da bioquímica, da biofísica, da biomecânica, da cinesia, da sinergia funcional, e da patologia de órgãos e sistemas do corpo humano e as disciplinas comportamentais e sociais, conforme apresentado no portal (COFFITO, s.d.).

Ainda na saúde pública o fisioterapeuta pode atuar no Núcleo de Assistência à Saúde da Família (NASF), que age em conjunto com a Estratégia Saúde da Família (ESF), baseando-se nos princípios da integralidade, intersetorialidade, com ações voltadas para a promoção de saúde e qualidade de vida dos usuários (SOUZA, et al, 2013).

\section{Conforme Teixeira (2011), o Sistema} Único de Saúde (SUS), pode ser considerado como uma "Política de Estado", sendo que, as ações e serviços de saúde oferecidos pelos órgãos e instituições públicas federais, estaduais e municipais, da administração direta e indireta e das fundações mantidas pelo Poder Público dão origem a esse sistema.

Recentemente, foi criado o Serviço de Atenção Domiciliar (SAD), regulamentado pela portaria $\mathrm{n}^{\circ} 963$, de 27 de maio de 2013, no qual o fisioterapeuta se faz presente, como opção para o atendimento ao usuário (BRASIL, 2013).

Assim sendo, justificou-se a execução deste trabalho devido à necessidade de, tanto os profissionais da área da saúde quanto a população que é usuária do serviço, conhecer a respeito da real função do fisioterapeuta e respectivas atuações, principalmente na esfera pública, visto que esse profissional encontra-se apto a promover e educar em saúde, além de contribuir para o bem estar geral. Ao qual se objetivou revisar na literatura a inserção da Fisioterapia na Saúde Coletiva no Brasil.

\section{METODOLOGIA}

Esse trabalho é uma revisão narrativa sobre a inserção do fisioterapeuta na saúde pública. Foi realizada uma busca bibliográfica nas bases, SCIELO, LILACS, BVS e Google Acadêmico.

A busca foi realizada nos meses fevereiro e março de 2015, após a pesquisa foram selecionados os documentos que se encaixavam nos seguintes critérios de elegibilidade: que versassem sobre a Fisioterapia na saúde pública e que possuíssem no máximo cinco anos de publicação.

Quanto aos meios ou procedimentos técnicos adotados para a coleta de dados, a pesquisa em questão é bibliográfica porque foi realizada a leitura, a análise e a interpretação de livros, sites e artigos científicos para construção do referencial teórico. Além disso, para acessar as leis, decretos, regulamentos e portarias sobre a Fisioterapia e sua 
atuação no âmbito público, foram acessados o Conselho Federal de Fisioterapia e Terapia Ocupacional e os documentos do Ministério da Saúde.

A presente pesquisa por ter caráter bibliográfico, não realizando entrevistas, aplicação de técnicas ou tratamentos, ou seja, não tendo o sujeito como seu objeto de estudo, e sim o arsenal bibliográfico, não necessitou da submissão ao Comitê de Ética e Pesquisa (CEP).

\section{RESULTADOS E DISCUSSÃO}

A instalação do Sistema Único de Saúde em nosso país, juntamente com a execução de seus objetivos como equidade, universalidade e integralidade, têm servido de base para profissionais e gestores elaborarem modelos assistências que condizem com seus princípios, além de serem referências nas propostas de financiamento. Por isso, muitas profissões como fisioterapeuta, nutricionista, farmacêutico, assistente social, estão adaptando-se aos novos modelos assistenciais da saúde, e cada vez mais a sua não participação representa uma falha no sistema da saúde pública (JUNIOR, 2010).

O profissional fisioterapeuta dentro de suas competências, e através de seus saberes, também está apto a colaborar na prevenção de doenças, quando atuando em outros níveis de atenção a saúde. Dessa maneira a Fisioterapia na saúde pública proporciona e estimula o controle de elementos que culminam no desenvolvimento da doença. Possuindo habilidades para desenvolver ações na atenção básica, tais como promoção e prevenção em saúde em diferentes grupos (mulheres, idosos, homens, crianças, gestantes), fornecendo orientações quanto a postura, conscientização e informações sobre saneamento básico, melhores condições de moradia, estimular hábitos de vida saudáveis, ações de controle de problemas cinético-funcionais, bem como estimular a participação da comunidade na saúde coletiva. (JÚNIOR, 2010).

Contrapondo o autor supracitado, Formiga e Ribeiro (2012) ressaltam que o destaque da assistência fisioterapêutica prioriza o trabalho nos serviços de atenção secundária e terciária, sendo esta uma característica decorrente da sua criação, por ter a medicina como base, em especial a fisiatria, a qual encontra-se vinculada ao modelo biomédico.

Aveiro et al. (2011), afirma que o fisioterapeuta pode desenvolver ações de prevenção e promoção da saúde, no aspecto da saúde mental, com terapias em grupos, também estimulando a socialização, utilizando-se da cinesioterapia, atividades que estimulam o cognitivo, e a memória no caso de idoso.

Sendo assim conforme Sousa e Ribeiro (2011), os serviços da Fisioterapia dentro do sistema de saúde pública no Brasil, podem-se fazer presentes na atenção primária, atuando nos Núcleos de assistência à Saúde da Família (NASF's), juntamente com as Equipes de Saúde da Família (ESF's); na atenção secundária, com serviços especializados em centros de reabilitação ou ambulatórios, que dispõem de ferramentas mais aprimoradas tecnologicamente; e na atenção terciária destacam-se nos ambientes hospitalares.

De acordo com Silva e Silveira (2011), que realizaram um estudo de abordagem qualitativa, que objetivou identificar a concepção dos acadêmicos de Fisioterapia acerca da humanização nas suas práticas, observou-se que a formação do fisioterapeuta constitui-se de uma grade curricular consolidada e inflexível, demonstrando a falta de conectividade entre o conteúdo apresentado. Considerando também uma profissão recente, com pouco mais de trinta anos, que vem evoluindo e 
conquistando sua autonomia, porém ainda vinculada ao modelo curativista, necessitando de ampliação quanto a sua atuação, que possam fomentar em transformações nos aspectos éticos, sociais, políticos.

Corroborando o estudo dos autores suprarreferidos, Formiga e Ribeiro (2012), enfocam que a participação do fisioterapeuta no cenário da atenção básica ainda é considerada em processo de elaboração, visto que, tem de ser iniciado desde a formação, onde esses profissionais possam ser instruídos para trabalhar nestes serviços.

A formação do fisioterapeuta não deve ser somente focada em técnicas, mas também no indivíduo de forma global, seja social e humana, sendo o principal recurso desse profissional as mãos, o toque, assim o contato, o envolvimento com o outro, sendo a recuperação desse instrumento uma forma de humanizar o atendimento, e melhorar a qualidade deste (SILVA; SILVEIRA, 2011).

Ainda segundo Júnior (2010), a Fisioterapia precisa adequar-se ao cenário sanitário atual, não visando o abandono à reabilitação, e sim agregar conhecimentos e valores à saúde no âmbito coletivo.

A Fisioterapia ainda tem como importante recurso, a epidemiologia, podendo ser usada para traçar e conhecer o perfil epidemiológico da população e utilização da assistência fisioterapêutica por parte destes, bem como no estudo do estabelecimento e aperfeiçoamento de técnicas, métodos de intervenção e tratamento em Fisioterapia (CARDOSO; JÚNIOR, 2013).

Em seu estudo de revisão sistemática, Portes et al. (2011), evidenciou as principais categorias de atuação fisioterapêutica no que se refere a atenção básica, sendo estas: educação em saúde, atividade domiciliar, atividade de grupo, investigação epidemiológica e planejamento das ações, atividades interdisciplinares, atuações acadêmicas, atendimento individual nas unidades básicas de saúde (UBS), atenção aos cuidadores, atuações intersetoriais e acolhimento (PORTES et al., 2011).

Em um estudo de caráter descritivo, com abordagem quali-quantitativo, foi identificado que as principais atividades desenvolvidas pelo fisioterapeuta no NASF foram a reabilitação e o acompanhamento em casos de paralisia cerebral, alterações congênitas, dores crônicas relacionadas à coluna, doenças osteomioarticulares, e Acidente Vascular Cerebral (AVC) (SOUSA; RIBEIRO, 2011)

Quanto à atuação do fisioterapeuta na saúde pública, segundo Júnior (2010), o saber inerente às práticas triviais da profissão, apresentam-se ainda falhos para a identificação das condições de risco, para desempenhar efetivamente suas funções de acordo com as necessidades apresentadas pela saúde pública. O fisioterapeuta além de interagir com os profissionais de saúde precisa relacionar-se com diferentes profissionais, como os antropólogos, filósofos, engenheiros, pedagogos, devendo também expandir seus conhecimentos nas práticas epidemiológicas, para maior compreensão das doenças, seus fatores de risco, e o melhor método de intervenção para prevenir.

\section{CONSIDERAÇÕES FINAIS}

Diante do exposto, conclui-se que a participação do fisioterapeuta na atenção básica, é imprescindível, bem como na saúde pública, em todos os níveis, visto que esse profissional encontra-se habilitado para desenvolver ações de promoção, prevenção e educação em saúde, sem perder a sua relevância na reabilitação. 
A formação acadêmica em especial do fisioterapeuta, ainda deixa a desejar no sentido da conscientização do importante papel desempenhado por esse profissional no âmbito público, estando voltada para a assistência no período em que a patologia está presente, tendo esse profissional a capacidade para atuar antes mesmo desse processo, assim evitando-o.

O fisioterapeuta nos últimos anos vem sendo inserido na atenção primária e perdendo o perfil de profissional apenas reabilitador, podendo participar das equipes multiprofissionais destinadas ao planejamento, implementação, controle e execução de programas e projetos de ações em atenção básica de saúde. No entanto, essa função do fisioterapeuta ainda é pouco conhecida até mesmo entre os profissionais da saúde e pelos usuários de saúde.

$$
\text { Contudo, faz-se necessário o }
$$
desenvolvimento de novos estudos que investiguem em campo, se o perfil do profissional fisioterapeuta já está mudando e, se este possui o devido reconhecimento quanto a sua atuação na saúde pública.

\section{REFERÊNCIAS}

AVEIRO, M.C.; ACIOLE, G.G.; DRIUSSO, P.; OISHI, J. Perspectivas da participação do fisioterapeuta no Programa Saúde da Família na atenção à saúde do idoso. Ciência \& Saúde Coletiva, 16(Supl. 1):1467-1478, 2011.

Portaria no 963, de 27 de maio de 2013.

Redefine a Atenção Domiciliar no âmbito do Sistema Único de Saúde (SUS), 2013.

CARDOSO, C.; JÚNIOR, J. P. B. Fisioterapia e saúde coletiva: reflexões, fundamentos e desafios / organizador José Patrício Bispo Júnior. São Paulo: Hucitec, 2013.
COFFITO, Conselho Federal de Fisioterapia e Terapia Ocupacional. Disponível em: <http://www.coffito.org.br/site/index.php/Fisioterap $\mathrm{ia} /$ definicao.html>.

DELAI, K.D.; WISNIEWSKI, M.S.W. Inserção do fisioterapeuta no Programa Saúde da Família. Ciência \& Saúde Coletiva, 16(Supl. 1):1515-1523, 2011.

FORMIGA, N. F. B.; RIBEIRO, K. S. Q. S. Inserção do Fisioterapeuta na Atenção Básica: uma Analogia entre Experiências Acadêmicas e a Proposta dos Núcleos de Apoio à Saúde da Família (NASF). Revista Brasileira de Ciências da Saúde, v. 16, n. 2, p. 113-122, 2012.

JÚNIOR, J.P.B. Fisioterapia e saúde coletiva: desafios e novas responsabilidades profissionais. Ciência \& Saúde Coletiva, 15(Supl. 1):1627-1636, 2010.

PORTES, L.H.; CALDAS, M.A.J.; PAULA,L.T.; FREITAS, M.S. Atuação do fisioterapeuta na atenção básica à saúde: uma revisão da literatura brasileira. Rev. APS; 2011; jan/mar; 14(1); 111 119, 2011.

SILVA, I.D.; SILVEIRA, M.F.A. A humanização e a formação do profissional em Fisioterapia. Ciência \& Saúde Coletiva, 16(Supl. 1):1535-1546, 2011.

SOUSA, A.R.B.; RIBEIRO, K.S.Q.S. A rede assistencial em Fisioterapia no município de João Pessoa: uma análise a partir das demandas da atenção básica. Revista Brasileira de Ciências da Saúde, v. 15, n. 3, p. 357-368, 2011.

SOUZA, M.C.; BOMFIM, A.L.; SOUZA, J. N.; BATISTA, T. F. Fisioterapia e Núcleo de Apoio à Saúde da Família: conhecimento, ferramentas e desafios. O Mundo da Saúde. São Paulo; 37(2):176-184, 2013.

TEIXEIRA, C. Os princípios do sistema único de saúde. Texto de apoio elaborado para subsidiar o debate nas Conferências Municipal e Estadual de Saúde. Salvador, Bahia. Junho de 2011. 